\title{
Blended Tools for Remote Sensing
}

\author{
$\mathrm{Mu}-\mathrm{Lin} \mathrm{Wu}$ \\ Diwan College of Management \\ Taiwan
}

\section{Introduction}

The mission of this chapter is to address that blended remote sensing tools can work more effectively than one single type of remote sensing software package, even several combined packages. In solving real world problems, remote sensing is usually not working alone. Geographic information systems (GIS), global positioning systems (GPS), and remote sensing are implemented simultaneously. Blended remote sensing tools can make GIS, GPS, and remote sensing more user-friendly. College students with blended remote sensing tools training can implement commercial remote sensing software packages more effectively. Productivity of college students can be promoted in critical thinking and problem solving by remote sensing technology.

National park management has to look into conservation, research, recreation, and environmental education simultaneously( $\mathrm{Wu}$ et al., 2001). One type of brand-name commercial software for national park management has its draw back. It was simply not good enough, even not user-friendly. Blended tools were then developed to solve many different types of problems relevant with environment and land. House management for land use enforcement at a watershed(Chang et al., 2001), water resource protection(Wu et al., 2001; Wu et al., 2002; Wu et al., 2003a), sewage management(Wu et al., 2003b), forest management for a county government( $\mathrm{Wu}$ et al., 2004), and remote sensing education at college(Wu et al., 2006; Wu et al., 2007) were real world problems have been solved by blended remote sensing tools since 2001.

The basic idea behind blended remote sensing tools is quite simple and straight forward. One software package can do a nice job and several software packages with a little bit of computer programming will do a much better job. Blended remote sensing tools can save several problems simultaneously with less budget and more efficiently. Blended tools can be customized to meet one particular technician's requirement in order to solve environmental problems in a period of time. Blended remote sensing tools were developed to provide different functions in a changing world. File format is the key component that blended remote sensing tools can be working smoothly among several different software packages and platforms. File compression is also a must when remote sensing is implemented to solve problems associated with high resolution images. Remote sensing application is usually a web type of job that file size has to be monitored all the time.

Computer programming is not a must when blended remote sensing tools were developed. But a little bit of computer programming would make blended remote sensing tools more 
user-friendly. Computer programming can leave to some specialists. In college remote sensing education, the instructors can ask some brilliant students to do computer programming. For the most of students, they would only modify several lines of computer codes. Trying to keep computer programming as simple as possible is critical when blended remote sensing tools would be working as expected. Easy to use and everyone likes to use are two important factors that blended remote sensing tools can be useful and operational. Working side by side with brand-name commercial software packages is usual a must for blended remote sensing tools. Software packages cited in this chapter are simple that they are available and useful.

\section{How Blended Remote Sensing Tools Were Made}

\subsection{Problems Identified and Well Defined}

Blended remote sensing tools for college education are a little bit different with those implemented in real world. The number of students enrolled in a remote sensing class is usually more than 30. Every student has one set of tools for homework assignment and computer jobs. Software packages providing full function that can be tried and tested for a period of time can only be implemented. Outside campus, budget is the major concern when a government agency would like to ask blended remote sensing tools be made. For research and teaching, software packages can be tried and tested are almost a must.

Problems can be solved by remote sensing technology alone are usually no needs for blended remote sensing tools to be made. In the first place, real world problems can be solved with GIS, GPS, and remote sensing simultaneously will find blended remote sensing tools useful. Remote sensing can not solve all kinds of problems but can solve some identified problems. Problems should be identified and well defined such that GIS, GPS, and remote sensing would work properly as expected.

Remote sensing and GIS software packages are available and powerful in the commercial market. GPS functions are usually provided with GIS software packages working in a mobile device for outdoor implementations. How many types of tools would be used is decided by what kind of problems to solve and how problems to be solved. Nine types of tools had been adopted for solving real world problems such as college remote sensing education (Wu et al., 2007a). Blended remote sensing tools were consisting of followings:

Remote sensing packages: ERMapper, PG-STEAMER(Pixoneer Geomatics, 2009); GIS packages: ArcMap, ArcPad; 3-D interactive graphics: Alice (Carnegie Mellon University, 2009); image enhancement: PG-STEAMER, SnagIt (Techsmith, 2009); image publishing for web mapping: MapViewSVG, Alice; advanced mathematics: MatLab; image file format editor: ECW header editor; image compression: ECW image compressor; development of application modules and database management: Visual Basic, Visual C++, Visual Basic.NET, Visual C\#.NET (Wu et al., 2007a).

MapObject made by ESRI can be added using Visual Basic or Visual C\# to make it as major components (Wu et al., 2007c; $\mathrm{Wu}$ et al., 2007d). The instructor has to do most of the computer jobs when students knew nothing about Visual C\# or Visual Basic. The students only modified several lines of compute codes and jobs were done accordingly.

Teechart for Net can be implemented for statistical implementations (Steema Software, 2009). HyperCAM (Hyperionics Technology, 2009) can be used to capture the action from one's Windows screen and save it to an AVI (Audio-Video Interleaved) movie file. 


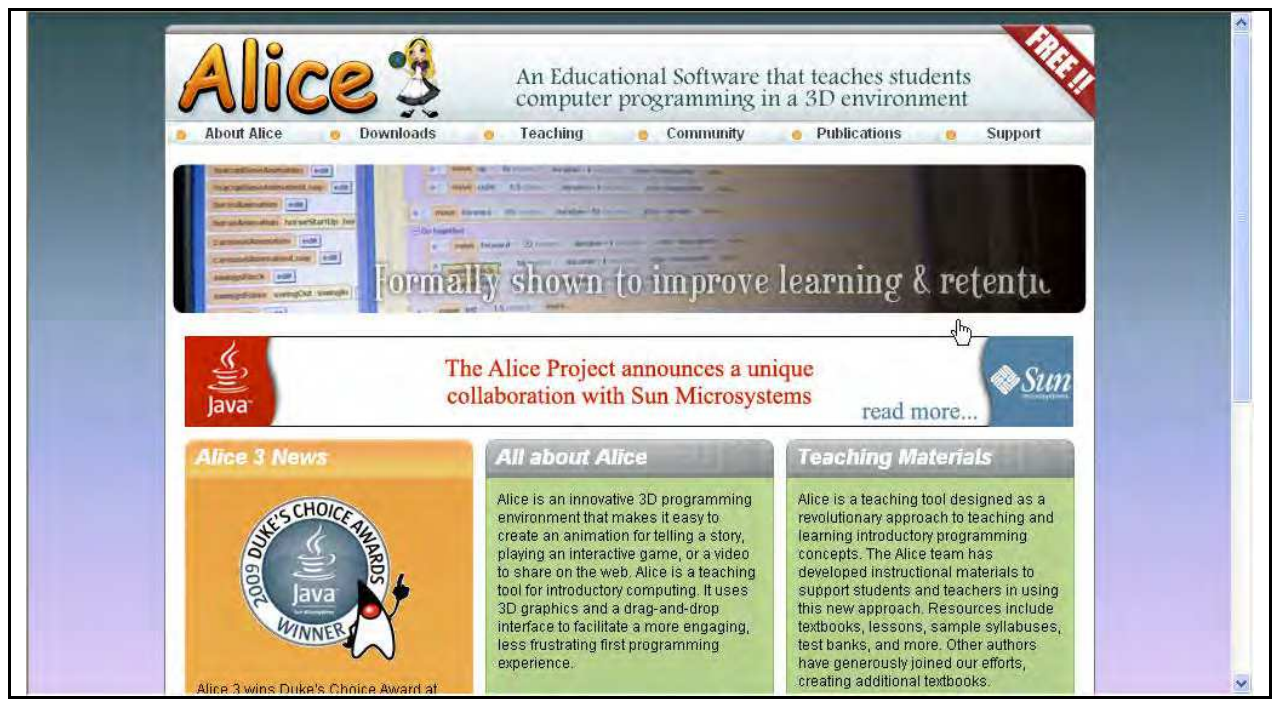

Fig. 1. Alice web site. (http://www.alice.org/)

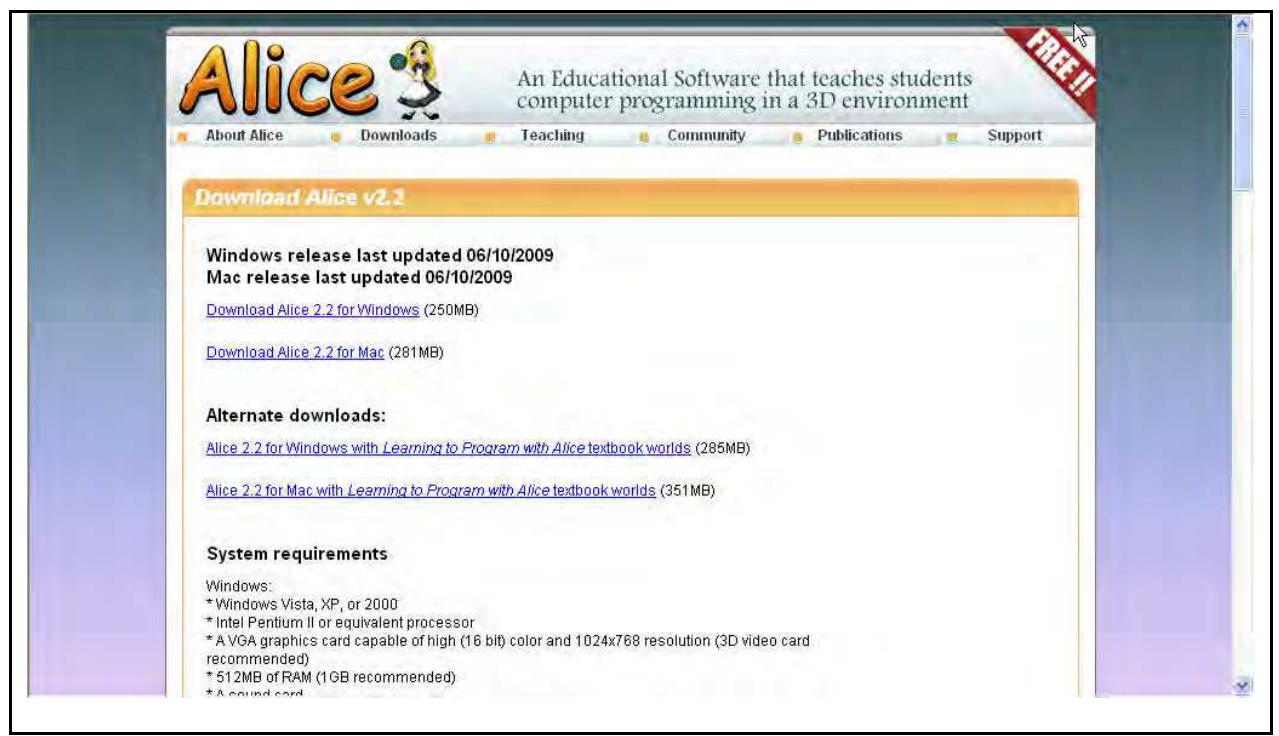

Fig. 2. Download Alice 2.2. 


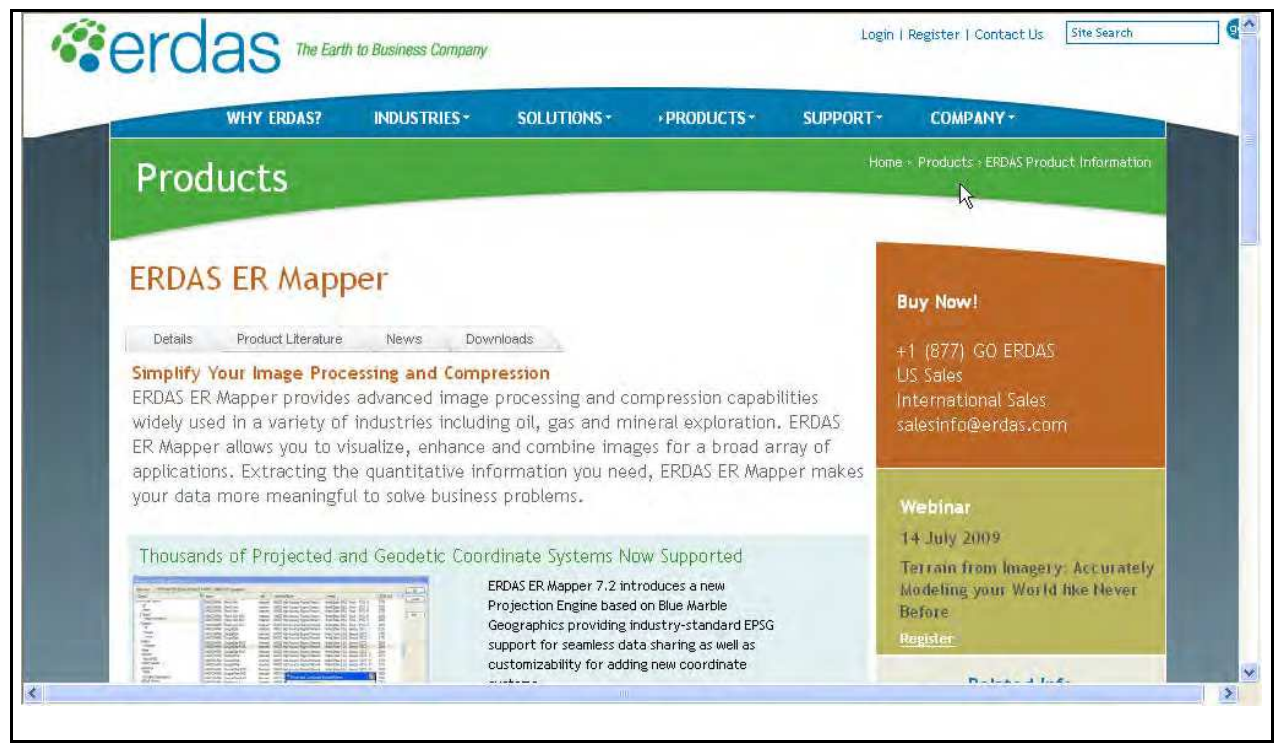

Fig. 3. ERDAS ER Mapper. (http://www.ermapper.com)

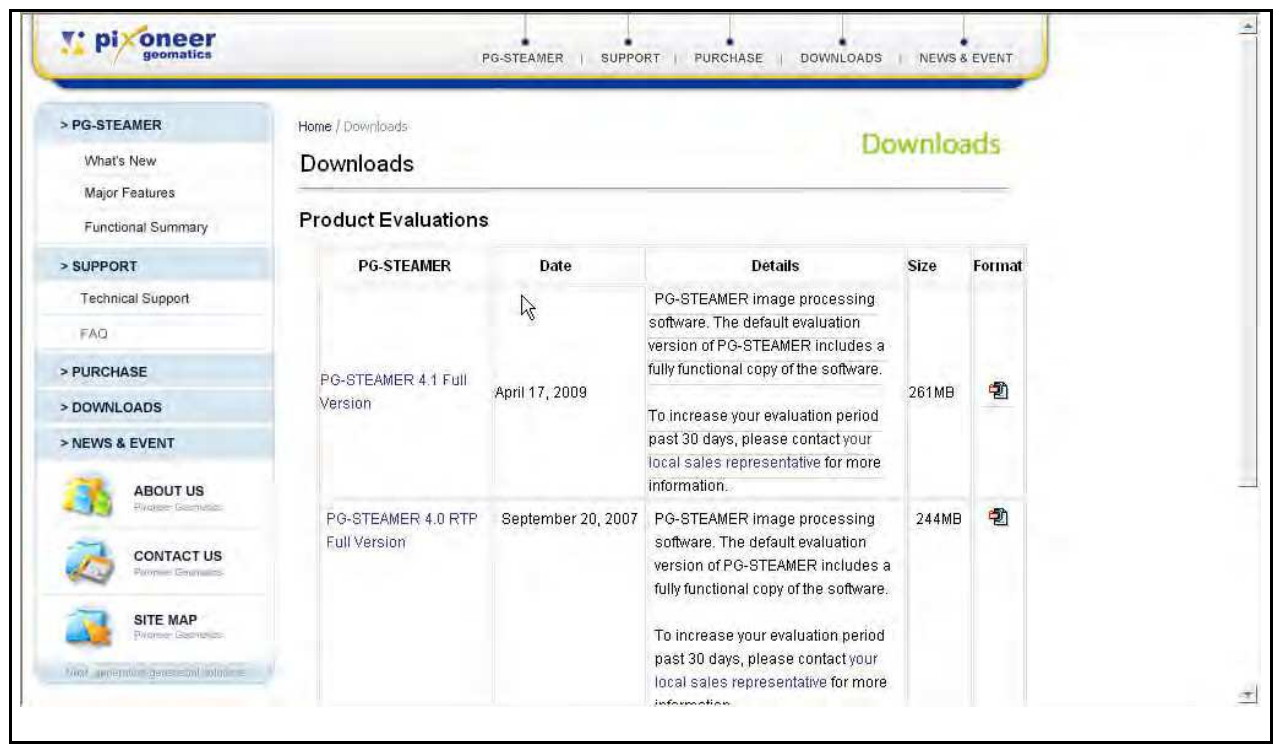

Fig. 4. PG-STEAMER downloads. (http://www.pixoneer.com/) 


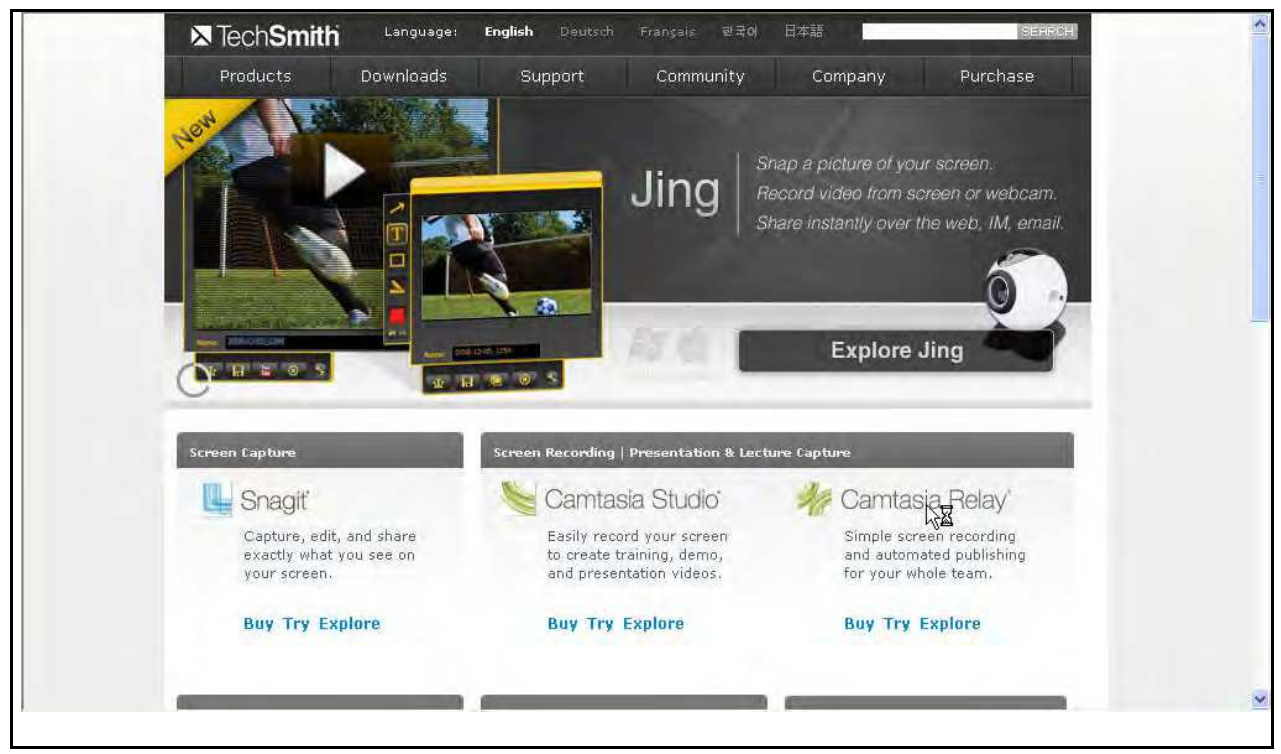

Fig. 5. SnagIt download.( http://www.techsmith.com/)

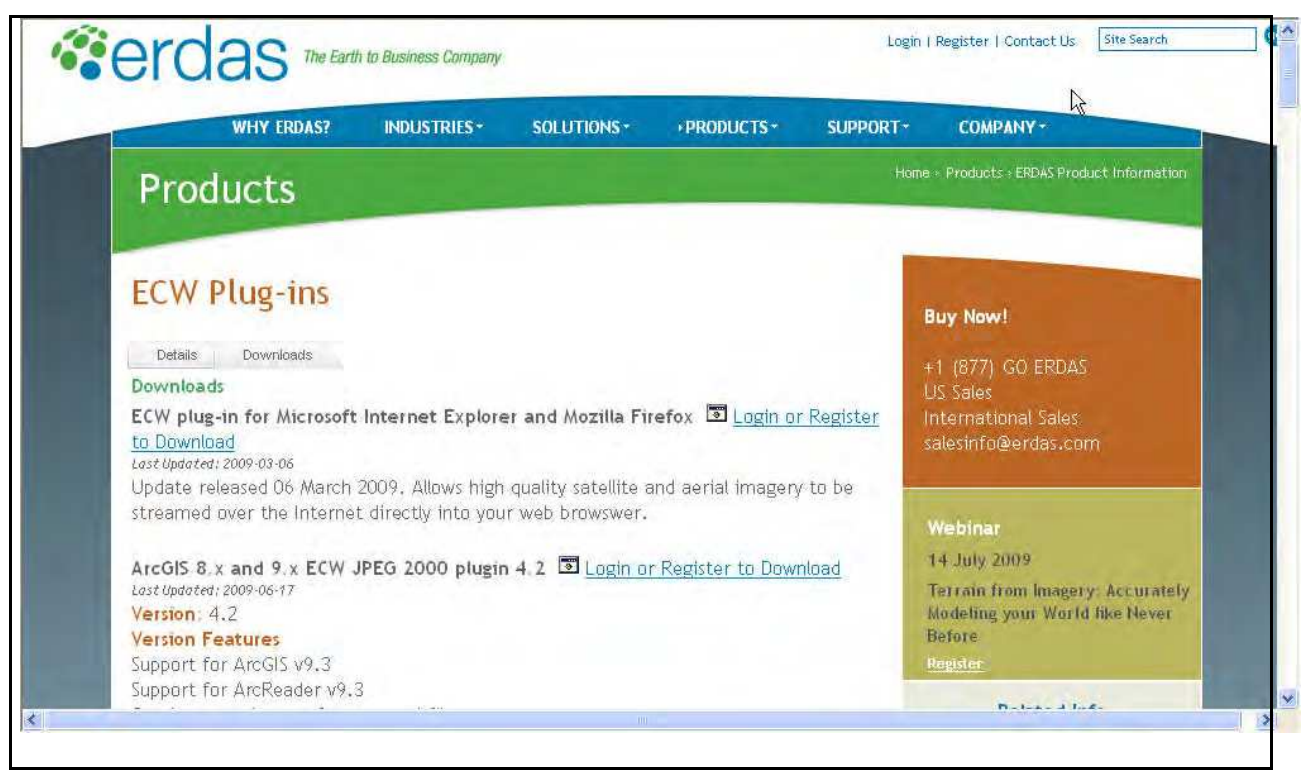

Fig. 6. ECW plug-in downloads. (http://www.ermapper.com) 


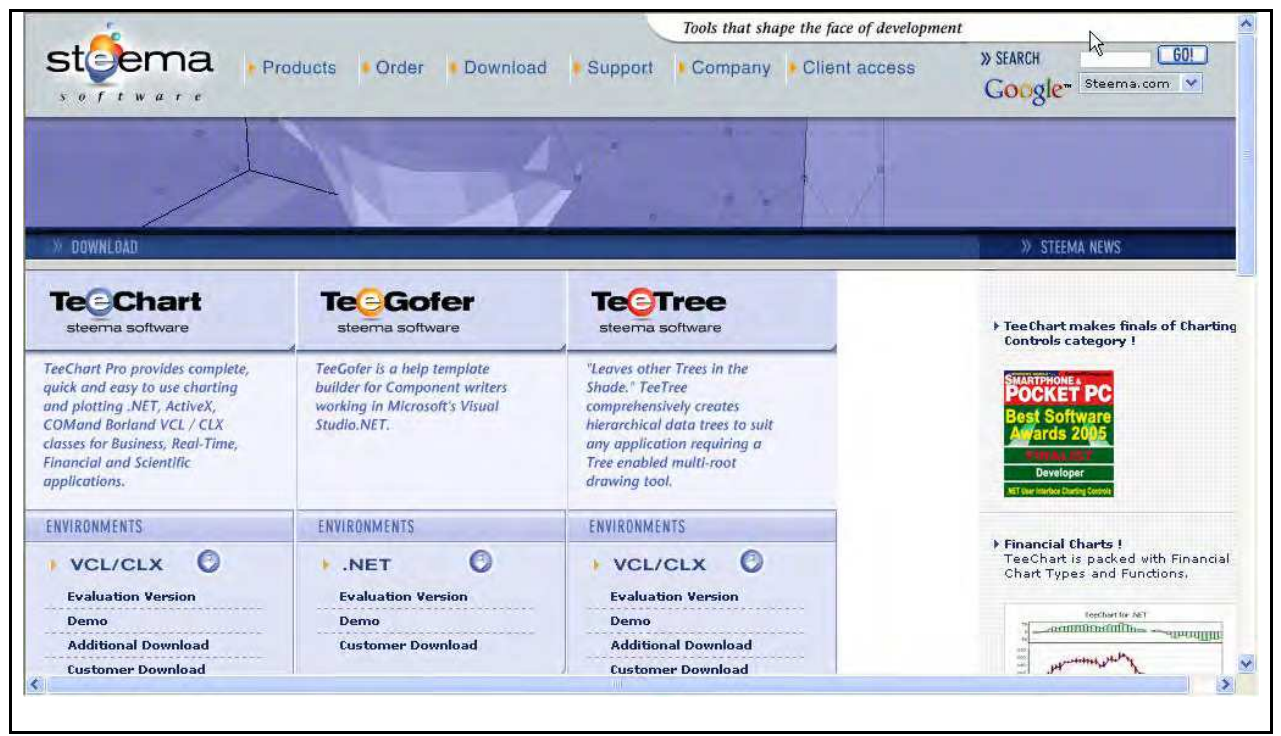

Fig. 7. Teechart downloads. (http://www.steema.com/)

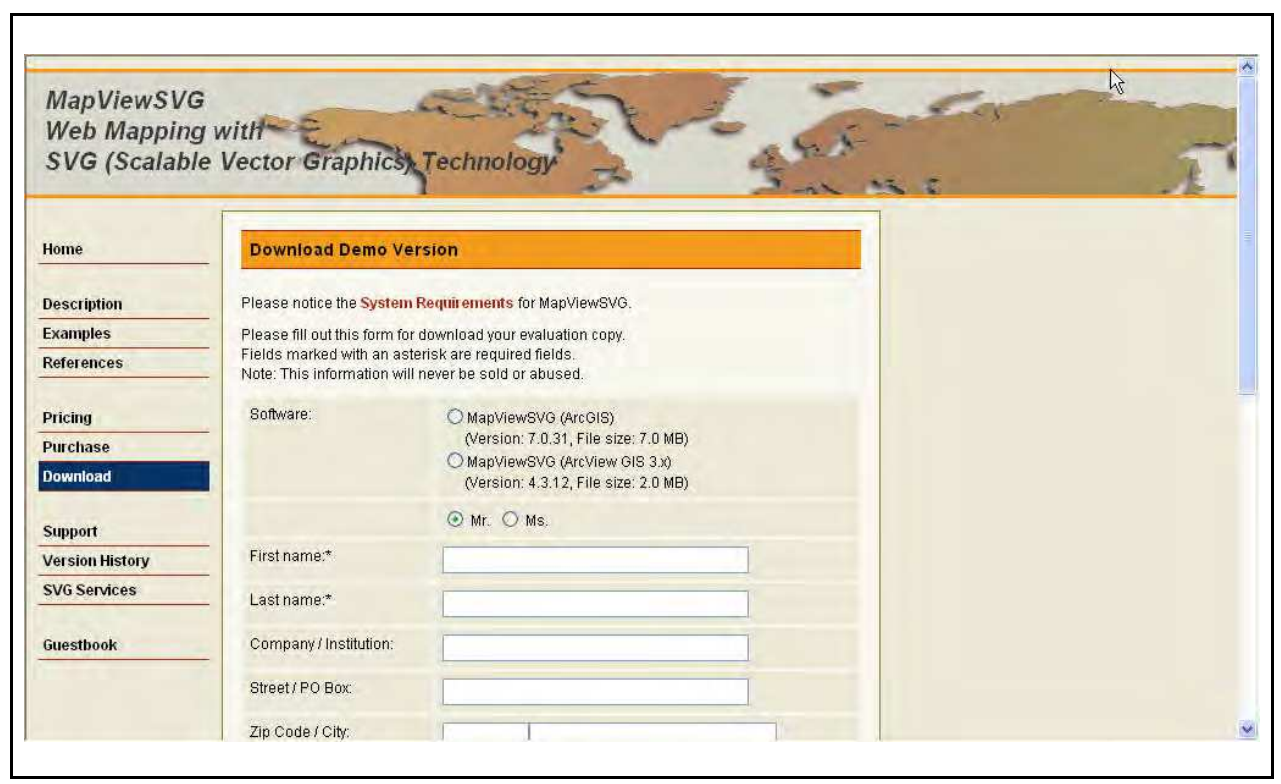

Fig. 8. MapViewSVG download. (http://www.mapviewsvg.com)

\subsection{Working Procedure}

Remote sensing software packages such as ERMapper or PG-STEAMER can be used for typical remote sensing implementations (Wu et al., 2007a). Digital images were manipulated and enhanced by PG-STEAMER or SnagIt to improve their information contributions. The 
coordinate information for a given pixel is very important for digital images to overlay with relevant maps. The ECW header editor program was used to retain and manipulate coordinate information of digital images. ArcGIS and ArcPAD made by ESRI were used to enhance integration of remote sensing and GIS. Database management in remote sensing was manipulated by computer programs using Visual Basic.NET and Visual C\#.NET. Alice was used to make 3-D interactive graphics for web page implementations. Remote sensing images can be published for web mapping in SVG (scalable vector graphics) file format using MapViewSVG.

\section{Functions Provided by Blended Remote Sensing Tools}

Functions provided by blended remote sensing tools may not be confined to every single tool involved. Computer programming and system integration would make blended remote sensing tools more powerful. Image file format conversion is one of the basic functions which blended remote sensing tools can provide. Image compression is essential and critical when high quality of images was used, especial in the case of PDA (personal digital assistant). An ECW file can be small as $1.6 \mathrm{MB}$ instead of its counter part, TIFF, $46 \mathrm{MB}$. Change detections can be done in a more easy way because of image enhancement and manipulations provided by blended remote sensing tools. Database management can be done in a simple and customized version when Visual Baisc.NET or Visual C\#.NET was used. Web publishing is usually a must that blended remote sensing tools have to support. Management problems encountered in a government office or in the open fields would be solved by several different types of application modules. Blended remote sensing tools would serve as the major components in these application modules.

\section{Application Modules for Solving Identified Management Problems}

An image extraction module for quick review of images, a 3-D Application module, and a web application module were made by some college students (Wu et al., 2007a). The 3-D application module developed by one senior college student can be used for extractions of terrain animation done by PG-STEAMER, web pages showing interactive 3-D graphics done by Alice, and an image extraction program for remote sensing image files with ECW file format.

An image processing module developed by one college student and a statistical application module made by a college student using TeeChart were shown in reference (Wu et al., 2007c). A GIS application module made by a college student showing tracking and inquiry capability of one's home town indicated that blended remote sensing tools could provide GIS functions as well (Wu et al., 2007c).

A database management module made by a student using Visual Basic.NET which provided functions for easy and quick retrieval of digital images (Wu et al., 2007d). An application module for extraction of tourist attraction site information was also developed in the same publication.

House management in a government agency was usually working with traditional management information systems. Remote sensing can provide very detail information for a given house because of digital maps at a scale of 1:1000. One township was investigated house by house to tag house locations on digital orthophoto maps with its house address 
number. There were more than 6,500 houses and about 121,000 hectares had been investigated and created as house databases in 2006. The house databases were very useful in agricultural mapping and monitoring for a county government. Blended remote sensing tools were developed to make the house databases more useful in agricultural management (Wu et al., 2007b). Management on a house basis was easy with the help of a GPS device and PDA because it was not difficult to find the right path to get the right location of a given house. Change detection of house information in the period 2003 to 2006 could be done easily. This information was very important in urban planning and agricultural management. Field operations, agricultural mapping and monitoring, and web publishing were three more types of functions provided by blended remote sensing tools for a county government (Wu et al., 2007b).

\section{Conclusions}

Remote sensing education at college is usually done by textbooks teaching and computer job assignments. This chapter indicated blended remote sensing tools can be made for college teaching. Cases had been discussed in application modules made by college students using software packages in the blended remote sensing tools and computer programming with four types of computer languages. Digital image compression, file format conversion, image enhancement, database manipulation, interactive 3-D graphics, image retrieval and manipulations, terrain animation, GIS integration, and web publishing of remote sensing images were functions provided by the blended remote sensing tools. College students can have some experiences on system integration of these application modules to solve one given management problem with the help of computer programming. The blended remote sensing tools are good for college students to gain better computer programming and system integration capabilities in addition to traditional remote sensing capabilities.

House management for a county government using blended remote sensing tools had been discussed to indicate how a real world problem can be solved. Blended remote sensing tools can be modified based on request made by any customer. Blended remote sensing tools can make house management in agricultural monitoring and mapping more user-friendly and effectively. Agricultural mapping and monitoring can provide detailed information for a given house such as where it was, who lives there, and what can be done. Blended remote sensing tools can be used to make some application modules for agricultural mapping and monitoring to solve problems encountered in agricultural management. Blended remote sensing tools can solve real world problems which were well identified and defined. Blended remote sensing tools were designed to solve problems that are suitable for GIS, GPS, and remote sensing working together.

\section{References}

Carnegie Mellon University, (2009). Alice 2.2, http:/ / www.alice.org/

Chang, Y.; Tai, S.; Song, D.; Liu, S. \& Wu, M. (2001). House Management for Land Use Enforcement at a Watershed Using a Self-Developed Web-Based GIS, Proceedings of International Geoscience and Remote Sensing Symposium (IGARSS 2001), Sydney, Australia, July 2001, 3 pages.

Earth Resource Mapping Pty Ltd. (2002). ER Mapper ECW ActiveX SDK, Release 2.46, 304 pages. 
Hyperionics Technology, (2009). HyperCAM, http:/ /www.hyperionics.com/

Pixoneer Geomatics, (2009). PG-STEAMER, http:/ / www.pixoneer.com/

Steema Software, (2009). Teechart for Net, http:/ / www.steema.com/

Techsmith, (2009). SnagIt, http:/ / www.techsmith.com/

Wu, M.; Lin, Y.; Yang, J. \& Chung, C.(2001). National Park Management Using SelfDeveloped and Web-Based Geographic Information Systems, Proceedings of International Geoscience and Remote Sensing Symposium (IGARSS 2001), Sydney, Australia, July 2001, 3 pages.

Wu, M.; Chen, C. \& Song, D. (2001). A Self-Developed and Web-Based Geographic Information System for Water Resource Protection, Proceedings of the 20th International Cartographic Conference (ICC 2001), Beijing, China, August 2001, 7 pages.

Wu, M.; Chen, C.; Tai, S.; Chou, W. \& Huang, H. (2001). Remote Sensing Applications in Water Resource Protection. Proceedings of the 22nd Asian Conference on Remote Sensing (ACRS 2001), Vol. 1, pp. 706-711, Singapore.

Wu, M.; Chen, C.; Liou, S. \& Wey, J. (2002). Mobile Geographic Information Systems for Water Resource Protection. Proceedings of Asian Conference on Remote Sensing (ACRS 2002), Kathmandu, Nepal, November 2002, 4 pages.

Wu, M.; Chen, C.; Liu, S. \& Wey, J. (2003). Implementations of Remote Sensing, GIS, and GPS for Water Resources and Water Quality Monitoring, Proceedings of Asian Conference on Remote Sensing (ACRS 2003), BEXCO Busan, Korea, November 2003, 3 pages.

Wu, M.; Chen, C.; Chou, W. \& Huang, H. (2003). Implementations of Geographic Information Systems on Sewage Management for Water Resources Protection, Proceedings of Asian Conference on Remote Sensing (ACRS 2003), BEXCO Busan, Korea, November 2003, 3 pages.

Wu, M.; Chen, S.; Fu, C.; Fan, J.\& Fu, S.(2004). Development of a Government GIS for Forest Management at Hsinchu County in Taiwan. Proceedings of the International Symposium on Remote Sensing 2004 \& 20th Anniversary of the Korean Society of Remote Sensing (2004 ISRS), October 2004, Jeju, Korea, 4 pages.

Wu, M.; Tai, S.; Chou, W.; Song, D.; Liu, S. \& Yang, T. (2004). Task-Oriented GIS for Water Management at Taipei Water Resource District, Proceedings of the International Symposium on Remote Sensing 2004 \& 20th Anniversary of the Korean Society of Remote Sensing (2004 ISRS), Jeju, Korea, October 2004, 3 pages.

Wu, M.; Liu, W.; Chang, Y. \& Lu, J. (2004). GIS for Decision Support of Water Resource Management at Taipei Water Management Office in Taiwan, Proceedings of the International Symposium on Remote Sensing 2004 \& 20th Anniversary of the Korean Society of Remote Sensing (2004 ISRS), Jeju, Korea, October 2004, 3 pages.

Wu, M.; Wang, Y.; Fang, C. \& Huang, Y. (2006). An Image Information System for Management of Watersheds in Remote Sensing Education, Proceedings of IEEE Geoscience and Remote Sensing Society ( IGARSS 2006), pp.2017-2020, Denver, CO, U. S. A., July 31 to August 4, 2006.

Wu, M.; Chu, C.; Wang, Y.; Wong, D. \& Hwang, M. (2007), Blended Tools for Remote Sensing Education, Proceedings of 2007 IEEE International Geoscience And Remote Sensing Symposium (IGARSS 2007), pp. 2217-2219, July 2007, Barcelona, Spain. 
Wu, M.; Chu, C.; Wang, Y.; Wong, D. \& Hwang, M. (2007), Blended Remote Sensing Tools for House Management, Proceedings of 2007 IEEE International Geoscience And Remote Sensing Symposium (IGARSS 2007), pp.1986-1989, Barcelona, Spain, July 2007.

Wu, M.; Chu, C.; Wong, D. ;Wang, Y. \& Hwang, M. (2007), Remote sensing and GIS integration for college GIS education, Proceedings of The 28th Asian Conference on Remote Sensing (ACRS 2007), November 2007, Kuala Lumpur, Malaysia, 6 pages.

Wu, M.; Wong, D. ; Chu, C.; Wang, Y. \& Hwang, M. (2007). Innovation problem solving methodologies for college remote sensing education, Proceedings of the 28th Asian Conference on Remote Sensing (ACRS 2007), Kuala Lumpur, Malaysia, November 2007, 5 pages. 


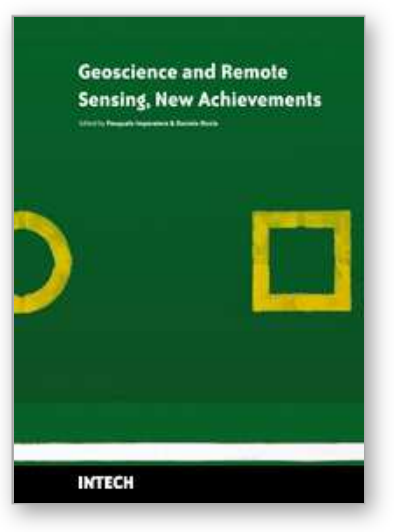

\author{
Geoscience and Remote Sensing New Achievements \\ Edited by Pasquale Imperatore and Daniele Riccio
}

ISBN 978-953-7619-97-8

Hard cover, 508 pages

Publisher InTech

Published online 01, February, 2010

Published in print edition February, 2010

Our planet is nowadays continuously monitored by powerful remote sensors operating in wide portions of the electromagnetic spectrum. Our capability of acquiring detailed information on the environment has been revolutionized by revealing its inner structure, morphology and dynamical changes. The way we now observe and study the evolution of the Earth's status has even radically influenced our perception and conception of the world we live in. The aim of this book is to bring together contributions from experts to present new research results and prospects of the future developments in the area of geosciences and remote sensing; emerging research directions are discussed. The volume consists of twenty-six chapters, encompassing both theoretical aspects and application-oriented studies. An unfolding perspective on various current trends in this extremely rich area is offered. The book chapters can be categorized along different perspectives, among others, use of active or passive sensors, employed technologies and configurations, considered scenario on the Earth, scientific research area involved in the studies.

\title{
How to reference
}

In order to correctly reference this scholarly work, feel free to copy and paste the following:

Mu-Lin Wu (2010). Blended Tools for Remote Sensing, Geoscience and Remote Sensing New Achievements, Pasquale Imperatore and Daniele Riccio (Ed.), ISBN: 978-953-7619-97-8, InTech, Available from: $\mathrm{http}: / /$ www.intechopen.com/books/geoscience-and-remote-sensing-new-achievements/blended-tools-forremote-sensing

\section{INTECH}

open science | open minds

\section{InTech Europe}

University Campus STeP Ri

Slavka Krautzeka 83/A

51000 Rijeka, Croatia

Phone: +385 (51) 770447

Fax: +385 (51) 686166

www.intechopen.com

\section{InTech China}

Unit 405, Office Block, Hotel Equatorial Shanghai

No.65, Yan An Road (West), Shanghai, 200040, China

中国上海市延安西路65号上海国际贵都大饭店办公楼405单元

Phone: +86-21-62489820

Fax: $+86-21-62489821$ 
(C) 2010 The Author(s). Licensee IntechOpen. This chapter is distributed under the terms of the Creative Commons Attribution-NonCommercialShareAlike-3.0 License, which permits use, distribution and reproduction for non-commercial purposes, provided the original is properly cited and derivative works building on this content are distributed under the same license. 